\title{
Use of Dual Protection Among Female Sex Workers In Swaziland
}

\begin{abstract}
CONTEXT: Female sex workers are at heightened risk of both HIV infection and unwanted pregnancy. Nonbarrier modern contraceptives are highly effective at preventing pregnancy, but offer no HIV protection. A better understanding of sex workers' use of condoms and nonbarrier methods is needed to help them meet their contraceptive and STI protection needs.
\end{abstract}

METHODS: A 2011 respondent-driven sampling survey collected reproductive health and contraceptive use data from 325 female sex workers in Swaziland. Multinomial logistic regression analysis was used to identify associations between selected characteristics and four outcomes of contraceptive use over the past month: consistent condom use alone; nonbarrier modern contraceptive use (either alone or with inconsistent condom use); dual method use; and inconsistent condom use, other method use or nonuse. Adjusted predicted probabilities were also calculated to determine patterns of association.

RESULTS: After adjustments were made for background and behavioral factors, $16 \%$ of female sex workers were found to be consistent users of condoms alone; 39\% used nonbarrier modern methods (without consistent condom use); $8 \%$ were dual method users; and $38 \%$ were inconsistent condom users or used other methods or none. Women who reported recent condom failure were less likely than others to be consistent condom users (6\% vs. 22\%). Consistent use of condoms alone was more common among women who had had no noncommercial partners in the past month than among those who reported two or more such partners (39\% vs. $3 \%$ ). In addition, respondents who had children were more likely than their nulliparous counterparts to report use of nonbarrier methods alone $(65 \%$ vs. 14\%).

CONCLUSIONS: Inconsistent or no condom use among nonbarrier contraceptive users underscores the need to incorporate HIV prevention into family planning interventions, particularly among female sex workers who have children and noncommercial partners.

International Perspectives on Sexual and Reproductive Health, 2013, 39(2):69-78, doi: 10.1363/3906913

Female sex workers are at high risk of both HIV infection and unintended pregnancy. Although programs and policies targeting female sex workers emphasize HIV prevention and condom promotion, they typically pay limited attention to the family planning needs of these women.

Correct and consistent condom use is highly effective at preventing HIV and other STIs, but condoms are not the most effective contraceptive method. ${ }^{1}$ In contrast, nonbarrier modern contraceptive methods (such as oral contraceptives, injectables and sterilization) are highly effective at preventing pregnancy, but confer no protection against STIs. For protection against both unwanted pregnancy and STIs, one option is a dual method approach: consistent use of condoms in conjunction with a more effective nonbarrier method. However, for many women-particularly female sex workers, who have frequent sex with multiple partners-the use of two methods for every sex act may be burdensome and unrealistic. For these women, a more feasible dual protection strategy might be a singlemethod approach: consistent condom use alone.

Most dual protection research has taken place in de- veloped countries, where contraceptive prevalence is relatively high. The reported prevalence of dual method use among American women ranges from $7 \%$ to $38 \%{ }^{2-7} \mathrm{~A}$ handful of studies on dual protection have been conducted in Sub-Saharan Africa, where both HIV and unwanted pregnancy are critical public health challenges. In South Africa and Botswana studies, dual method use at last sex ranged from $4 \%$ to $28 \%{ }^{8-11}$ However, a limitation of most research on dual protection is the focus on method use at last sex, rather than consistency of simultaneous condom and other contraceptive use at each coital act. These "last sex" measures of dual method use may not reflect optimal dual protection against both pregnancy and disease.

Little is known about the dual protection strategies employed by female sex workers, and measurement of their contraceptive behaviors is complicated by the fact that their condom use varies across partners. Specifically, female sex workers use condoms less consistently with more intimate, noncommercial partners than with paying clients. ${ }^{12-14}$ In addition, their reported condom use at last sex or with their most recent partner likely will not accu-

\section{By Eileen A. Yam, Zandile Mnisi, Xolile Mabuza, Caitlin Kennedy, Deanna Kerrigan, Amy Tsui and Stefan Baral}

Eileen A. Yam is HIV/AIDS associate, Population Council, Washington, DC, USA. Zandile Mnisi is HIV/STI advisor, Swaziland $\mathrm{Na}$ tional AIDS Program, Ministry of Health, Mbabane, Swaziland. Xolile Mabuza is executive director, House of Hope, Mbabane, Swaziland. Caitlin Kennedy is assistant professor, Department of Health; Deanna Kerrigan is associate professor, Department of Health, Behavior and Society; Amy Tsui is professor, Department of Population, Family and Reproductive Health; and Stefan Baral is assistant scientist, Department of Epidemiology-all at Johns Hopkins Bloomberg School of Public Health, Baltimore, MD, USA. 
rately represent their consistency of use. ${ }^{15}$ Furthermore, in contrast to studies among established couples, it may not be appropriate to classify female sex workers as dual method users based on responses to a standard survey question asking about current contraceptive use (i.e., a "check all that apply" question with all methods listed). Sex workers may state that they use condoms in response to this question, despite the fact that they use condoms only as an HIV or STI prevention measure with some partners. ${ }^{14,16}$ Hence, to assess dual protection use among female sex workers, measures must account for the consistency of dual method use across partners, rather than relying solely on reported contraceptive methods, or on method use with the most recent partner.

The HIV prevalence in Swaziland is among the highest in the world, with $32 \%$ of adults living with HIV. ${ }^{17}$ Women are disproportionately burdened by the epidemic: Among 20-24-year-olds, the odds of infection among women are more than three times those among men. ${ }^{18}$ In a study that enrolled Swazi women who were HIV-negative at baseline,${ }^{17} \mathrm{HIV}$ incidence was 3.1 per 100 person-years after six months of follow-up. The highest incidence was among the age-groups 20-24 and 35-39 (4.2\% and 4.1\%, respectively). Furthermore, the odds of having seroconverted by follow-up among unmarried women were three times those among married or cohabiting women. Heterosexual transmission is the primary driver of the HIV epidemic in Swaziland, and one in six heterosexual couples are HIVdiscordant. ${ }^{18}$ Forty-eight percent of married women report use of modern contraceptives, as do $63 \%$ of sexually active, unmarried women. The most commonly used methods are injectables and male condoms. Nevertheless, a substantial proportion of women in Swaziland have an unmet need for contraception, and just one-third of births among Swazi women are wanted at the time of pregnancy. ${ }^{18}$

By examining current contraceptive use as well as consistency of condom use in the past month, this study aims to describe the dual protection strategies of female sex workers in Swaziland, a country with extremely high HIV prevalence and moderately high use of modern contraceptive methods. We assessed condom use consistency by asking about use over the past month, rather than categorizing condom use solely on whether women listed condoms as a "current contraceptive method." In particular, we wanted to determine how female sex workers who protect themselves against both HIV and pregnancy are different from those who protect themselves against one or the other, or against neither. This study elucidates the sexual and reproductive health needs of this vulnerable population, and provides evidence to support increased attention to the dual protection needs of Swazi female sex workers.

\section{METHODS}

\section{Sampling and Study Protocol}

Data were collected in a survey of Swazi female sex workers conducted from July to September 2011. Because no sampling frame exists for this population in Swaziland, we used respondent-driven sampling to identify and recruit participants; this approach is a variant of snowball sampling and employs mathematical adjustments to account for the nonrandom nature of the sampling process. ${ }^{19,20}$ The research team identified nine initial participants ("seeds"), each of whom received three recruitment coupons to recruit other sex workers. Staff gave each of these recruits three coupons with which to recruit up to three other women, and so forth.

Eligibility criteria were being 16 or older, providing informed consent in English or siSwati, presenting a valid recruitment coupon, and responding affirmatively to a statement attesting that they had exchanged or sold sex for money, favors or goods in the past 12 months. Interviewers administered an hour-long questionnaire that asked about demographic characteristics, sexual and reproductive health knowledge and behaviors, and other social and behavioral characteristics. Because of the potentially low literacy levels of participants, coupled with confidentiality concerns of women engaging in stigmatized, criminalized behaviors, staff obtained oral consent from participants rather than written consent. Interviews took place at a centrally located, voluntary HIV-testing clinic. The institutional review board at Johns Hopkins Bloomberg School of Public Health and the scientific and ethics committee of Swaziland's Ministry of Health approved the study protocol.

\section{Dependent Variables}

The outcome measures were based on participants' responses to a series of questions regarding contraceptive and condom use. Interviewers read participants a list of contraceptive methods with the following instructions: "For each method I mention, please tell me if you are currently using it. Some women use more than one method, so you can say more than one." Participants were considered to be users of a nonbarrier modern method if they used the pill, the injectable, the IUD, the implant or sterilization.

To classify women as consistent condom users, we used women's responses to questions about condom use with different partners. First, we asked about condom use with new clients: "In the last 30 days, how often did you use condoms (male or female) when having vaginal sex with new clients?" Response options were "never," "rarely," "sometimes," "most of the time" or "always." Interviewers repeated this question when asking participants about condom use with "regular clients" and with "noncommercial partners." Participants were considered to be consistent condom users if they reported that they had always used condoms in the past month with each type of partner. Because not all women reported on all three partnership types, participants were also considered consistent condom users if they stated that they had always used condoms in the past month with all reported partners. Using these responses, we created a four-category outcome variable for condom and contraceptive use $(0=$ inconsistent condom use, other method use or nonuse; $1=$ consistent use of condoms only; $2=$ use of a nonbarrier modern meth- 
od, either alone or with inconsistent condom use; and $3=$ dual method use). Dual method users were those who both used condoms consistently and reported current use of a nonbarrier modern method.

\section{Independent Variables}

For social and demographic characteristics, we collected information on participants' recruitment zone (Matsapha/ Manzini, Mbabane or Piggs Peak/Lavumisa), age, highest education level (primary or less, some secondary, completed secondary or more), marital status (ever-married or ever cohabited vs. never-married or never cohabited), number of children and income in the past month. Participants also reported on their HIV status ("Have you ever been told by a health care provider that you have HIV?"), current receipt of HIV treatment, current pregnancy intention, and pregnancy and abortion history.

Sexual behavior measures included the numbers of new clients, regular clients and noncommercial partners in the past month. The section of the questionnaire regarding "regular clients" included the following preface: "Next, I am going to ask you about your regular clients or regular paying partners. [These individuals] are those whom you have had sex with at least three times in your life and who have paid you for sex. This may also include longtime clients [who] help you pay for your living expenses or provide you with other financial support."

Finally, to measure condom failure, we created a binary variable based on women's responses to a question asked three times, once for each type of partner: "In the last 30 days, have you had sex with a new client/regular client/ noncommercial partner when the condom has slipped off or broken?" Those who responded affirmatively for any partner type were categorized as having experienced condom failure.

\section{Analysis}

We used Stata version 11.0 to conduct all analyses. We first conducted exploratory data analysis to examine variable frequencies, as well as to assess missing data and illogical values. The variables for numbers of new and regular clients in the past month had the highest proportions of missing values ( $4.9 \%$ and $2.8 \%$, respectively). These missing values were imputed by assigning the average number of each client type reported by other participants who had been sex workers for the same amount of time as the woman with the missing values. Missing values for all other variables were handled by listwise deletion.

For univariate statistics, we report both crude percentages and estimates adjusted for respondent-driven sampling (RDS). Such adjustment consists of applying variablespecific weights to account for two potential biases of the RDS methodology: the tendency for participants to recruit others like themselves (homophily), and the variation in network sizes of different individuals. ${ }^{20}$ RDS adjustments were originally conceived for univariate population inference, and there is limited consensus on appropriate methods for ad- justing such estimates in analyses involving more than one variable. ${ }^{21}$ Therefore, in this analysis, we present unadjusted estimates for the bivariate and multivariate analyses.

We conducted multinomial logistic regression analysis to estimate the predicted adjusted probability of each of the four condom and contraceptive use categories, and to identify significant correlates of the outcomes. First, we ran a model that included only participants' background characteristics. Next, we added controls for behavioral and exposure variables: having received an HIV-positive diagnosis; reporting condom failure in the past month; and numbers of new clients, regular clients and noncommercial partners in the past month. Because of the small number of women in some of the outcome categories, we estimated parameter standard errors and constructed confidence intervals using a bootstrap procedure with 2,000 repetitions.

We used Wald statistics to determine whether and how to model continuous covariates as categorical variables, testing for which variable type yielded a better model fit. We also used likelihood-ratio tests to assess the overall relationship between the independent variables and the dependent variables. Multicollinearity was examined using variance inflation factors. To facilitate interpretation of the results from the multinomial analysis, we used the coefficients from the full model to calculate the adjusted predicted probability for each of the four possible condom and contraceptive use outcomes. ${ }^{*}$

\section{RESULTS \\ Sample Characteristics}

Among the 339 female sex workers who presented to the study clinic to complete the survey, 14 did not meet eligibility criteria and were excluded; hence, the final analytic sample included 325 women. After weighted estimates were calculated, $31 \%$ of the women were 20 or younger, $50 \%$ were aged $21-29$, and $20 \%$ were 30 or older (Table 1 , page 72 ). A third (33\%) of respondents had no more than a primary education, $55 \%$ had some secondary education and $12 \%$ had completed at least secondary school. Nine in 10 (91\%) women had never been married and had never cohabited, and the majority of women had children (32\% had one child and $39 \%$ had two or more). In the past month, 34\% of respondents had earned less than US\$70, $32 \%$ had earned \$70-140, 26\% had earned \$141-281 and $9 \%$ had earned at least $\$ 282 .{ }^{22}$

Almost half of female sex workers had tested positive for $\mathrm{HIV}$, and of those, $42 \%$ were receiving HIV treatment from a health care facility. Of the HIV-positive participants, nine in 10 had been pregnant, three-quarters had children and

\footnotetext{
*Using the parameters estimated in the multinomial logistic regression analysis, the formulas to calculate the predicted probabilities for each of the four outcome categories are

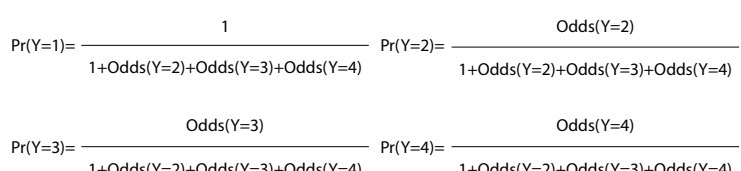

$1+O d d s(Y=2)+O d d s(Y=3)+O d d s(Y=4) \quad 1+O d d s(Y=2)+O d d s(Y=3)+O d d s(Y=4)$
} 
TABLE 1. Selected background, sexual behavior and contraceptive use characteristics of female sex workers, by crude and respondent-driven sampling (RDS) weighted percentages, Swaziland, 2011

\begin{tabular}{|c|c|c|c|c|c|}
\hline Characteristic & $\begin{array}{l}\text { Crude \% } \\
(\mathrm{N}=325)\end{array}$ & RDS-weighted \% & Characteristic & $\begin{array}{l}\text { Crude } \% \\
(\mathrm{~N}=325)\end{array}$ & RDS-weighted \% \\
\hline \multicolumn{3}{|l|}{ SOCIAL AND DEMOGRAPHIC } & \multicolumn{3}{|l|}{ No. of regular clients in past month } \\
\hline Recruitment zone & & & $0-1$ & 8.3 & $7.3(2.9-11.7)$ \\
\hline Matsapha/Manzini & 35.4 & nat & $2-4$ & 28.6 & $31.6(23.9-39.3)$ \\
\hline Mbabane & 36.0 & na & $5-10$ & 40.3 & $42.7(34.5-50.9)$ \\
\hline Piggs Peak/Lavumisa & 28.6 & na & $\geq 11$ & 22.8 & $18.4(12.3-24.5)$ \\
\hline \multicolumn{3}{|l|}{ Age } & \multicolumn{3}{|l|}{ Total no. of clients in past month } \\
\hline$\leq 20$ & 19.7 & $30.7(19.7-41.7)$ & $\leq 5$ & 17.2 & $18.2(11.4-25.0)$ \\
\hline $21-24$ & 25.2 & $22.8(16.1-29.5)$ & $6-10$ & 32.3 & $31.5(23.8-39.1)$ \\
\hline $25-29$ & 28.0 & $26.9(18.1-35.7)$ & $11-15$ & 17.9 & $19.7(12.9-26.6)$ \\
\hline$\geq 30$ & 27.1 & $19.6(13.1-26.0)$ & $\geq 16$ & 32.6 & $30.6(22.4-38.7)$ \\
\hline \multicolumn{3}{|l|}{ Education } & \multicolumn{3}{|c|}{ No. of noncommercial partners in past month } \\
\hline Primary or less & 32.6 & $32.6(25.4-39.7)$ & 0 & 11.4 & $8.6(3.9-13.4)$ \\
\hline Some secondary & 53.8 & $55.1(47.6-62.5)$ & 1 & 52.9 & $52.1(44.9-59.4)$ \\
\hline Completed secondary or more & 13.5 & $12.3(6.5-18.2)$ & $\geq 2$ & 35.7 & $39.2(31.7-46.7)$ \\
\hline \multicolumn{3}{|l|}{ Marital status } & \multicolumn{3}{|l|}{ Consistent condom use in past month } \\
\hline Ever-married/cohabited & 11.2 & $9.1(4.6-13.6)$ & With new clients & 74.0 & $68.8(60.0-70.6)$ \\
\hline \multirow[t]{2}{*}{ Never-married/never cohabited } & 88.8 & $90.6(86.4-95.4)$ & With regular clients & 48.2 & $46.8(37.5-56.0)$ \\
\hline & & & With noncommercial partners & 33.5 & $32.2(23.8-40.7)$ \\
\hline No. of children & & & With all partners & 23.5 & $22.5(14.2-30.7)$ \\
\hline 0 & 24.6 & $29.2(21.8-36.7)$ & & & \\
\hline 1 & 30.8 & $32.1(24.9-39.4)$ & Currently uses a nonbarrier & & \\
\hline$\geq 2$ & 44.6 & $38.6(30.8-46.4)$ & modern method & 46.9 & $51.1(43.3-58.9)$ \\
\hline \multicolumn{3}{|l|}{ Income in past month (US\$)‡ } & Ever used emergency contraception & 32.7 & $27.5(20.9-34.2)$ \\
\hline$\leq 69$ & 26.5 & $33.7(24.3-43.2)$ & & & \\
\hline 70-140 & 32.1 & $31.6(24.2-39.1)$ & Overall contraceptive use & & \\
\hline $141-281$ & 26.5 & $25.8(18.4-33.2)$ & Inconsistent condom use/ & & \\
\hline \multirow[t]{2}{*}{$\geq 282$} & 15.0 & $8.8(4.1-13.6)$ & other method use/nonuse & 38.1 & $36.0(28.6-43.5)$ \\
\hline & & & Consistent condom use only & 15.5 & $13.5(8.2-18.9)$ \\
\hline Received an HIV-positive diagnosis & 55.0 & $45.5(38.1-53.0)$ & Nonbarrier modern method without & & \\
\hline Receiving HIV treatment $(\mathrm{N}=175) \S$ & 40.0 & $41.5(29.1-53.8)$ & consistent condom use & 38.4 & $40.1(32.4-47.8)$ \\
\hline Currently trying to get pregnant & 14.7 & $13.7(8.2-19.3)$ & Dual method & 8.0 & $10.3(5.0-15.7)$ \\
\hline Ever been pregnant & 82.7 & $77.8(70.2-85.4)$ & & & \\
\hline \multirow{2}{*}{$\begin{array}{l}\text { Ever had an unwanted pregnancy } \\
(\mathrm{N}=267)+\dagger\end{array}$} & & & Condom failure in past month $\neq \neq$ & & \\
\hline & 50.2 & $48.7(39.6-57.8)$ & With new clients $(\mathrm{N}=292)$ & 28.4 & $23.0(16.2-29.8)$ \\
\hline \multirow[t]{2}{*}{ Ever had an abortion $(\mathrm{N}=266)++$} & 13.2 & $11.7(6.3-17.1)$ & With regular clients (N=302) & 39.7 & $36.7(28.8-44.6)$ \\
\hline & & & With noncommercial partners $(\mathrm{N}=207)$ & 41.1 & $32.5(22.4-42.6)$ \\
\hline \multicolumn{3}{|l|}{$\begin{array}{l}\text { SEXUAL BEHAVIOR/CONTRACEPTIVE USE } \\
\text { No. of new clients in past month }\end{array}$} & With any partner $(\mathrm{N}=323)$ & 55.3 & $47.5(39.3-55.7)$ \\
\hline $0-1$ & 13.5 & $16.5(10.4-22.6)$ & & & \\
\hline $2-4$ & 43.7 & $44.2(36.2-52.2)$ & & & \\
\hline $5-10$ & 33.2 & $32.9(25.2-40.5)$ & & & \\
\hline$\geq 11$ & 9.5 & $6.5(2.9-10.0)$ & & & \\
\hline
\end{tabular}

tRespondent-driven sampling adjustments take into account the probability of recruiting others like oneself (i.e., homophily). Since all participants recruited others from their same zone, there is no adjustment for this variable. $\neq 1 \mathrm{SZL}=\mathrm{US} \$ 0.14$, based on the exchange rate on August 1, 2011 (source: reference 22). §Among HIV-positive respondents. ††Among respondents who had ever been pregnant. ‡¥Among respondents who reported ever using condoms with a given partner type in the past 30 days. Notes: Figures in parentheses are $95 \%$ confidence intervals. RDS=respondent-driven sampling. na=not applicable.

nearly half had had an unwanted pregnancy (not shown).

Fourteen percent of all respondents said they were currently trying to get pregnant (we did not collect information on which partner they wished to get pregnant with). Seventy-eight percent of women had ever been pregnant, and of these, 49\% had had an unwanted pregnancy. Of respondents who had ever been pregnant, 12\% had had an abortion.

\section{Sexual Behavior and Contraceptive Use}

Overall, $51 \%$ of the female sex workers reported 6-15 clients in the past month, and $31 \%$ reported 16 or more. On average, they had had a larger number of regular clients than new clients over this period (8.4 vs. 5.3-not shown). Roughly half $(52 \%)$ of the participants had had one noncommercial partner in the last month, and 39\% had had two or more.

Sixty-nine percent of female sex workers reported consistent condom use with new clients in the past month, and $47 \%$ reported consistent use with regular clients; $32 \%$ had used condoms consistently with noncommercial partners, and $23 \%$ had done so with all partners in this period. Half $(51 \%)$ of the women were currently using a nonbarrier modern method, and 28\% had ever used emergency contraception. Overall, 36\% of respondents reported inconsistent condom use, other method use or nonuse; $14 \%$ had used condoms consistently; $40 \%$ had used a nonbarrier modern method (without consistent condom use); and $10 \%$ were dual method users (i.e., they reported both 
TABLE 2. Relative risk ratios (and 95\% confidence intervals) from multinomial logistic regression analysis assessing the likelihood of women reporting various contraceptive use behaviors rather than inconsistent condom use, other method use or nonuse, by selected background characteristics

\begin{tabular}{|c|c|c|c|}
\hline Characteristic & $\begin{array}{l}\text { Consistent condom } \\
\text { use only }(\mathrm{N}=50)\end{array}$ & $\begin{array}{l}\text { Use of nonbarrier modern } \\
\text { method without consistent } \\
\text { condom use }(\mathrm{N}=124)\end{array}$ & $\begin{array}{l}\text { Dual method use } \\
(\mathrm{N}=26)\end{array}$ \\
\hline \multicolumn{4}{|l|}{ Recruitment zone } \\
\hline Matsapha/Manzini (ref) & 1.00 & 1.00 & 1.00 \\
\hline Mbabane & $0.78(0.32-1.88)$ & $0.72(0.36-1.41)$ & $1.56(0.26-9.33)$ \\
\hline Piggs Peak/Lavumisa & $1.05(0.36-3.02)$ & $1.93(0.92-4.08)$ & $3.62(0.48-27.20)$ \\
\hline \multicolumn{4}{|l|}{ Age } \\
\hline$\leq 20$ (ref) & 1.00 & 1.00 & 1.00 \\
\hline $21-24$ & $0.65(0.18-2.39)$ & $0.51(0.17-1.47)$ & $0.78(0.02-25.98)$ \\
\hline $25-29$ & $0.67(0.16-2.73)$ & $0.37(0.12-1.15)$ & $0.32(0.01-17.73)$ \\
\hline$\geq 30$ & $0.68(0.17-2.67)$ & $0.13(0.04-0.47)^{* *}$ & $0.23(0.00-12.25)$ \\
\hline \multicolumn{4}{|l|}{ Education } \\
\hline \multicolumn{4}{|l|}{ Marital status } \\
\hline Ever-married/cohabited (ref) & 1.00 & 1.00 & 1.00 \\
\hline Never-married/never cohabited & $0.80(0.09-6.82)$ & $0.64(0.24-1.72)$ & $0.32(0.02-5.76)$ \\
\hline \multicolumn{4}{|l|}{ No. of children } \\
\hline 0 (ref) & 1.00 & 1.00 & 1.00 \\
\hline 1 & $0.68(0.21-2.20)$ & $4.81(1.87-12.35)^{* *}$ & $3.34(0.04-274.62)$ \\
\hline$\geq 2$ & $1.32(0.44-3.95)$ & $8.55(2.99-24.51)^{* * *}$ & $5.17(0.07-411.72)$ \\
\hline \multicolumn{4}{|l|}{ Income in past month (US\$)† } \\
\hline$\leq 140$ (ref) & 1.00 & 1.00 & 1.00 \\
\hline
\end{tabular}

${ }^{* *} \mathrm{p}<.01 .{ }^{* * *} \mathrm{p}<.001 .+1 \mathrm{SZL}=$ US\$0.14, based on the exchange rate on August 1,2011 (source: reference 22). Note: ref=reference group.

consistent condom use and nonbarrier modern method use). Nearly half (48\%) of women had experienced condom failure with any partner in the past 30 days.

Two women were missing condom use values for all three partner types and were excluded from subsequent analyses. Five women were missing values for current contraceptive method; those who did not report always using condoms in the past month were categorized as inconsistent condom users, nonusers or users of "other" methods. Among the 323 remaining participants, 24\% said they had always used condoms in the past month with all reported partners, including 16\% who had used condoms alone and $8 \%$ who had also used a nonbarrier modern method (not shown). Of the $77 \%$ of women who had not always used condoms in the past month with all partners, half reported using a nonbarrier modern method (either alone or with inconsistent condom use) and half reported using condoms inconsistently without a nonbarrier method; one respondent had used another method and three had used none.

\section{Multivariate Analysis}

In multinomial logistic regression analysis that controlled for women's background characteristics, respondents aged 30 or older were less likely than those 20 or younger to report use of a nonbarrier modern method (without consistent condom use), rather than inconsistent condom use, other method use or nonuse (relative risk ratio, 0.1-Table 2 ). In contrast, women who had one child or two or more children were more likely than those with no children to report such use of only a nonbarrier modern method (4.8 and 8.6, respectively). Other background characteristics were not associated with condom and contraceptive use.

In regression analysis that also controlled for HIV diagnosis, condom failure, and numbers of regular clients and noncommercial partners, women in the oldest age-group remained less likely than those in the youngest group to report use of a nonbarrier method (without consistent condom use), as opposed to inconsistent condom use, other method use or nonuse (relative risk ratio, 0.1-Table 3, page 74). As in the earlier model, women with one child or with two or more children were more likely than nulliparous women to report using a nonbarrier modern method (either alone or with inconsistent condom use), rather than to report inconsistent condom use, other method use or nonuse (5.2 and 9.1, respectively). Participants who had some secondary education were less likely than those with no more than a primary education to report consistent condom use, rather than inconsistent use, other method use or nonuse (0.3). Compared with respondents who reported no noncommercial partners in the past month, those who had had one such partner or at least two over this period were less likely to be consistent condom users (0.1 for each). In addition, women who had experienced recent condom failure were also less likely to report consistent condom use (0.2). Notably, having an HIV-positive diagnosis was not associated with method choice. 


\begin{tabular}{|c|c|c|c|}
\hline Variable & $\begin{array}{l}\text { Consistent condom } \\
\text { use only }(\mathrm{N}=50)\end{array}$ & $\begin{array}{l}\text { Use of nonbarrier modern } \\
\text { method without consistent } \\
\text { condom use }(\mathrm{N}=124)\end{array}$ & $\begin{array}{l}\text { Dual method use } \\
(\mathrm{N}=26)\end{array}$ \\
\hline \multicolumn{4}{|l|}{ Recruitment zone } \\
\hline Matsapha/Manzini (ref) & 1.00 & 1.00 & 1.00 \\
\hline Mbabane & $0.80(0.25-2.52)$ & $0.78(0.37-1.66)$ & $1.72(0.21-14.11)$ \\
\hline Piggs Peak/Lavumisa & $1.03(0.22-4.78)$ & $1.77(0.74-4.22)$ & $4.02(0.42-38.11)$ \\
\hline \multicolumn{4}{|l|}{ Age } \\
\hline$\leq 20$ (ref) & 1.00 & 1.00 & 1.00 \\
\hline $21-24$ & $0.86(0.17-4.43)$ & $0.53(0.16-1.76)$ & $0.79(0.01-72.24)$ \\
\hline $25-29$ & $0.68(0.13-3.57)$ & $0.37(0.11-1.27)$ & $0.33(0.00-38.73)$ \\
\hline$\geq 30$ & $0.77(0.13-4.45)$ & $0.10(0.03-0.40)^{* * *}$ & $0.24(0.00-30.24)$ \\
\hline \multicolumn{4}{|l|}{ Education } \\
\hline Primary or less (ref) & 1.00 & 1.00 & 1.00 \\
\hline Some secondary & $0.33(0.12-0.97)^{*}$ & $0.88(0.42-1.83)$ & $0.65(0.19-2.19)$ \\
\hline Completed secondary or more & $0.88(0.20-3.82)$ & $2.23(0.75-6.65)$ & $0.64(0.00-7,168.61)$ \\
\hline \multicolumn{4}{|l|}{ Marital status } \\
\hline Ever-married/cohabited (ref) & 1.00 & 1.00 & 1.00 \\
\hline Never-married/never cohabited & $0.75(0.08-7.35)$ & $0.70(0.22-2.19)$ & $0.31(0.01-6.76)$ \\
\hline \multicolumn{4}{|l|}{ No. of children } \\
\hline 0 (ref) & 1.00 & 1.00 & 1.00 \\
\hline 1 & $0.57(0.12-2.68)$ & $5.16(1.76-15.19)^{* *}$ & $3.48(0.06-194.42)$ \\
\hline$\geq 2$ & $1.20(0.31-4.70)$ & $9.12(2.84-29.24)^{* * *}$ & $4.97(0.08-292.67)$ \\
\hline \multicolumn{4}{|l|}{ Income in past month (US\$)† } \\
\hline$\leq 140$ (ref) & 1.00 & 1.00 & 1.00 \\
\hline$\geq 141$ & $1.26(0.39-4.07)$ & $1.32(0.63-2.79)$ & $2.06(0.62-6.85)$ \\
\hline \multicolumn{4}{|c|}{ Received an HIV-positive diagnosis } \\
\hline No (ref) & 1.00 & 1.00 & 1.00 \\
\hline Yes & $0.63(0.22-1.76)$ & $1.46(0.73-2.90)$ & $1.21(0.35-4.14)$ \\
\hline \multicolumn{4}{|l|}{ No. of new clients in past month } \\
\hline$\leq 4$ (ref) & 1.00 & 1.00 & 1.00 \\
\hline$\geq 5$ & $1.26(0.43-3.68)$ & $0.49(0.24-1.01)$ & $1.03(0.29-3.58)$ \\
\hline \multicolumn{4}{|c|}{ No. of regular clients in past month } \\
\hline $0-1$ (ref) & 1.00 & 1.00 & 1.00 \\
\hline $2-4$ & $0.12(0.01-1.76)$ & $1.62(0.15-17.06)$ & $0.55(0.00-8,407.66)$ \\
\hline$\geq 5$ & $0.15(0.01-2.07)$ & $0.95(0.09-9.94)$ & $0.53(0.00-7,122.40)$ \\
\hline \multicolumn{4}{|c|}{ No. of noncommercial partners in past month } \\
\hline 0 (ref) & 1.00 & 1.00 & 1.00 \\
\hline 1 & $0.11(0.02-0.69)^{*}$ & $0.71(0.10-5.02)$ & $0.17(0.01-3.39)$ \\
\hline$\geq 2$ & $0.12(0.02-0.78)^{*}$ & $1.05(0.14-7.63)$ & $0.36(0.02-6.29)$ \\
\hline \multicolumn{4}{|l|}{ Condom failure in past month } \\
\hline No (ref) & 1.00 & 1.00 & 1.00 \\
\hline Yes & $0.21(0.07-0.59)^{* *}$ & $1.16(0.58-2.33)$ & $0.37(0.10-1.45)$ \\
\hline
\end{tabular}

When we added pregnancy intention to the regression model, this covariate was associated only with nonbarrier modern method use $(0.2$; 95\% confidence interval, 0.07$0.64, \mathrm{p}<.01-$ not shown). Its inclusion did not significantly change any other associations. Because we were unable to ascertain the timing of method use and desire to get pregnant, we did not include fertility intention in the models presented here.

Using the coefficients (not shown) from the logistic regression models, we calculated the adjusted predicted probabilities of each of the four behavioral outcomes for each independent variable (Table 4). There were minimal differences between the adjusted probabilities and the actual probabilities (i.e., a one-percentage-point difference for both consistent condom use and nonbarrier modern methods). The adjusted probability of being an inconsistent condom user (or reporting other method use or nonuse) was 22\% for women 20 or younger and 69\% for those 30 or older. In contrast, the adjusted probability of using a nonbarrier modern contraceptive (without consistent condom use) was $61 \%$ for those in the youngest age-group and $12 \%$ for the oldest group. Nulliparous women had an adjusted probability of $64 \%$ of being in the inconsistent condom user group, while women with children had a 
probability of 20-22\%. Conversely, respondents with children had a $65 \%$ adjusted probability of using a nonbarrier modern contraceptive, whereas those without children had a $14 \%$ probability. The probability of being a consistent condom user was 39\% among women reporting no recent noncommercial partners and 3\% among those reporting at least two. Finally, women who reported condom failure in the past month were less likely than others to be consistent condom users ( $6 \%$ vs. $22 \%$ ).

\section{DISCUSSION}

Public health programs for female sex workers, where available, tend to focus on condom use and disease prevention. Our findings underscore the importance of characterizing and addressing the contraceptive needs of this understudied and underserved population. As has been demonstrated in previous studies, ${ }^{23,24}$ HIV-positive status was not associated with higher levels of consistent condom use or other contraceptive use. HIV-positive women are at risk not only of transmitting HIV to their partners, but also of experiencing unintended pregnancy and transmitting HIV to their infants. Furthermore, the use of nonbarrier contraceptives without supplemental condom use has been documented among HIV-positive women. ${ }^{23,24}$ Some women may hold the erroneous belief that nonbarrier contraceptive methods confer a protective benefit against the transmission of HIV and other STIs. The existence of this belief among Swazi female sex workers is worth exploring, since a large proportion were using such methods without accompanying consistent condom use.

Our findings suggest that female sex workers who have noncommercial-and often more intimate-partners are less likely than others to be protected against STIs and pregnancy. Echoing findings from studies conducted among females who are not sex workers, these data suggest that consistent condom use is less likely among sex workers who have noncommercial partners. Among sex workers who have just one such partner, concerns about pregnancy may outweigh concerns about disease acquisition or transmission, or nonpaying partners may be less willing to have protected sex..$^{25,26}$ In contrast, in their sexual relations with paying clients, the use of condoms is much more common.

The negative association between recent condom failure and consistent condom use is noteworthy. More than half of the participants had reported condom failure in the last month, which raises questions about the cause of such frequent breakage and slippage. Further investigation should consider both the quality of available condoms and condom-compatible lubricants, as well as female sex workers' knowledge about how to use condoms and lubricants correctly.

\section{Limitations}

This study has a number of limitations. Because the measurement of sensitive behaviors is difficult, participants' responses may reflect recall or social desirability bias. For example, female sex workers are regular targets of condom
TABLE 4. Adjusted predicted probabilities of various contraceptive use behaviors, by selected variables

\begin{tabular}{|c|c|c|c|c|}
\hline Variable & $\begin{array}{l}\text { Inconsistent } \\
\text { condom use/ } \\
\text { other method } \\
\text { use/nonuse }\end{array}$ & $\begin{array}{l}\text { Consistent } \\
\text { condom } \\
\text { use only }\end{array}$ & $\begin{array}{l}\text { Use of non- } \\
\text { barrier modern } \\
\text { method with- } \\
\text { out consistent } \\
\text { condom use }\end{array}$ & $\begin{array}{l}\text { Dual } \\
\text { method } \\
\text { use }\end{array}$ \\
\hline Adjusted predicted probability & 0.38 & 0.16 & 0.39 & 0.08 \\
\hline \multicolumn{5}{|l|}{ Recruitment zone } \\
\hline Matsapha/Manzini (ref) & 0.44 & 0.12 & 0.39 & 0.05 \\
\hline Mbabane & 0.43 & 0.10 & 0.36 & 0.11 \\
\hline Piggs Peak/Lavumisa & 0.31 & 0.08 & 0.45 & 0.16 \\
\hline \multicolumn{5}{|l|}{ Age } \\
\hline$\leq 20$ (ref) & 0.22 & 0.07 & 0.61 & 0.09 \\
\hline $21-24$ & 0.50 & 0.12 & 0.30 & 0.08 \\
\hline $25-29$ & 0.57 & 0.11 & 0.27 & 0.05 \\
\hline$\geq 30$ & $0.69^{*}$ & 0.15 & $0.12^{*}$ & 0.04 \\
\hline \multicolumn{5}{|l|}{ Education } \\
\hline Primary or less (ref) & 0.38 & 0.18 & 0.35 & 0.09 \\
\hline Some secondary & 0.45 & 0.07 & 0.41 & 0.07 \\
\hline Completed secondary or more & 0.30 & 0.07 & 0.59 & 0.04 \\
\hline \multicolumn{5}{|l|}{ No. of children } \\
\hline 0 (ref) & 0.64 & 0.18 & 0.14 & 0.04 \\
\hline 1 & $0.22^{*}$ & 0.04 & $0.65^{*}$ & 0.10 \\
\hline$\geq 2$ & $0.20^{*}$ & 0.04 & $0.65^{*}$ & 0.10 \\
\hline \multicolumn{5}{|l|}{ Income in past month (US\$)† } \\
\hline$\leq 140$ (ref) & 0.45 & 0.11 & 0.38 & 0.06 \\
\hline$\geq 141$ & 0.37 & 0.11 & 0.42 & 0.10 \\
\hline \multicolumn{5}{|l|}{ Received an HIV-positive diagnosis } \\
\hline No (ref) & 0.44 & 0.15 & 0.34 & 0.07 \\
\hline Yes & 0.39 & 0.08 & 0.45 & 0.08 \\
\hline \multicolumn{5}{|l|}{ No. of regular clients in past month } \\
\hline $0-4$ (ref) & 0.39 & 0.19 & 0.33 & 0.09 \\
\hline$\geq 5$ & 0.39 & 0.02 & 0.54 & 0.05 \\
\hline \multicolumn{5}{|c|}{ No. of noncommercial partners in past month } \\
\hline 0 (ref) & 0.22 & 0.39 & 0.25 & 0.15 \\
\hline 1 & 0.50 & 0.05 & 0.41 & 0.04 \\
\hline$\geq 2$ & 0.46 & $0.03^{*}$ & 0.46 & 0.05 \\
\hline \multicolumn{5}{|l|}{ Condom failure in past month $¥$} \\
\hline No (ref) & 0.35 & 0.22 & 0.31 & 0.11 \\
\hline Yes & 0.44 & $0.06^{*}$ & 0.45 & 0.05 \\
\hline
\end{tabular}

*The outcome value for the specified variable category is significantly different from that for the reference group at $\mathrm{p}<.05$. $+1 \mathrm{SZL}=\mathrm{US} \$ 0.14$, based on the exchange rate on August 1, 2011 (source: reference 22). ¥Among respondents who reported ever using condoms with a given partner type in the past 30 days. Note: ref=reference group.

promotion activities, and they may feel compelled to overreport condom use in an effort to satisfy interviewers. In addition, they may not accurately recall condom use during a given period of time. The ordering of questions about condom use could create bias as well. For example, for each type of partner, our questionnaire first asked women how consistently they had used condoms in the past month, and this question was immediately followed by asking if the woman had experienced condom breakage or slippage in that period. Among women who responded to the first question by reporting that they did not always use condoms in the past month, the subsequent question may have compelled them to falsely report condom failure as a justification for inconsistent condom use. This could lead to overreporting of condom failure. 
Another limitation is that we asked participants about their "current" contraceptive use, whereas the question about condom use referred to the past 30 days. In creating the outcome variable, we made the assumption that contraceptive use reported at the time of the survey also applied to the previous month. However, some women may have started or stopped contraceptive use within the past month. We did not collect data on the timing of initiation or termination of the current contraceptive method, and we are unable to estimate what proportion of women may have switched methods in the past month. Feldblum and colleagues reported that, among Malagasy female sex workers who were using a nonbarrier method at baseline, $65 \%$ switched to condoms or no method during the 18-month follow-up. ${ }^{27}$ However, it is unlikely that method switching was this frequent in the 30-day reporting period on which our analysis is based.

The present findings are based on a sample of women from a hidden population engaging in a behavior that is both stigmatized and criminalized. The use of respondentdriven sampling facilitated recruitment and data collection, and provided information that allows for the adjustment of univariate statistics to account for differences in network size and homophily. However, as with any hidden population with no sampling frame, the generalizability to the broader female sex worker population in Swaziland is limited. Furthermore, recent respondent-driven sampling assessments suggest that adjusted univariate statistics should be interpreted with caution, because this approach is a relatively new methodology for which empirical evidence is limited. ${ }^{28,29}$

\section{Conclusions}

Our findings provide meaningful and new information about the pregnancy and disease prevention behaviors of Swazi female sex workers, as well as further support for coupling HIV prevention and family planning services. The few programmatic interventions targeting Swazi female sex workers focus on condom distribution, but a more integrated sexual and reproductive health approach may better meet their dual protection needs. ${ }^{30}$ For example, the incorporation of contraceptive counseling and provision into HIV services-such as voluntary counseling and testing services or condom distribution programs-presents an opportunity to promote dual protection strategies that are appropriate and feasible for female sex workers. In settings where HIV services are already available to female sex workers, providers should be trained to assess their need for family planning, and they should offer counseling and methods. In Swaziland, peer outreach workers should also be trained to refer women to reproductive health services and to improve women's awareness of the importance of family planning. In addition, because little is known about female sex workers' beliefs about the safety and effectiveness of nonbarrier modern methods, surveillance research should be initiated to improve our understanding of their contraceptive knowledge and attitudes.
Programs, policies and research focused on female sex workers tend to be supported by donors and agencies that are focused on HIV prevention, and little attention is paid to the interrelation between these women's disease prevention and pregnancy prevention needs. Integration of services would be strengthened if strategic frameworks and donor initiatives explicitly called for programming that integrated reproductive health and HIV services. Supporting female sex workers' ability to plan or limit pregnancy is an important goal in itself, and family planning can prevent pregnancy-related health risks and reduce the levels of infant mortality and unsafe abortion. Furthermore, family planning is a cost-effective, feasible way to prevent HIV infection. By preventing unwanted pregnancy among women living with HIV, contraceptive use can help prevent the birth of infected babies and reduce the number of AIDS orphans. ${ }^{31,32}$ Among HIV-positive women in our sample, the vast majority had ever been pregnant and most had children. We could not determine the temporal order of HIV infection relative to pregnancy or childbirth, nor did we collect information on the HIV status of participants' children, but given the extremely high HIV prevalence among their mothers, there is ample risk that the children of Swazi female sex workers may be born with HIV.

This research calls attention to the dual protection needs of female sex workers, highlighting the relevance of family planning to HIV prevention efforts. In an atmosphere where female sex workers are often seen as vectors for heterosexual HIV transmission, the reality of these women's risk of unwanted pregnancy and vertical transmission is frequently neglected. The severe HIV epidemic in Swaziland demands a comprehensive, integrated response, and HIV prevention and family planning programs and policies can be mutually beneficial. A coordinated approach is necessary to minimize negative health consequences not only among female sex workers, but also among all Swazi women, their partners and their children.

\section{REFERENCES}

1. Hatcher RA et al., Contraceptive Technology, revised 20th ed., Atlanta, GA, USA: Ardent Media, 2011.

2. Bearinger LH and Resnick MD, Dual method use in adolescents: a review and framework for research on use of STD and pregnancy protection, Journal of Adolescent Health, 2003, 32(5):340-349.

3. Ford K, Sohn W and Lepkowski J, Characteristics of adolescents' sexual partners and their association with use of condoms and other contraceptive methods, Family Planning Perspectives, 2001 33(3):100-105\& 132.

4. Humphries HO and Bauman KE, Condom use by Norplant users at risk for sexually transmitted diseases, Sexually Transmitted Diseases, 1994, 21(4):217-219.

5. Peipert JF et al., Adherence to dual-method contraceptive use Contraception, 2011, 84(3):252-258.

6. Santelli JS et al., Combined use of condoms with other contraceptive methods among inner-city Baltimore women, Family Planning Perspectives, 1995, 27(2):74-78.

7. Santelli JS et al., The use of condoms with other contraceptive methods among young men and women, Family Planning Perspectives, 1997, 29(6):261-267. 
8. MacPhail $\mathrm{C}$ et al., Predictors of dual method use for pregnancy and HIV prevention among adolescent South African women, Contraception, 2007, 75(5):383-389.

9. Kleinschmidt I et al., Dual protection in sexually active women, South African Medical Journal, 2003, 93(11):854-857.

10. Morroni $C$ et al., Dual protection against sexually transmitted infections and pregnancy in South Africa, African Journal of Reproductive Health, 2003, 7(2):13-19.

11. Kraft JM et al., Use of dual protection in Botswana, Studies in Family Planning, 2009, 40(4):319-328.

12. Tran TN, Detels R and Lan HP, Condom use and its correlates among female sex workers in Hanoi, Vietnam, AIDS and Behavior, 2006, 10(2):159-167.

13. Wang $C$ et al., HIV prevalence, previous HIV testing, and condom use with clients and regular partners among Senegalese commercial sex workers, Sexually Transmitted Infections, 2007, 83(7):534-540.

14. Wayal S et al., Contraceptive practices, sexual and reproductive health needs of HIV-positive and negative female sex workers in Goa, India, Sexually Transmitted Infections, 2011, 87(1):58-64.

15. Noar SM, Cole C and Carlyle K, Condom use measurement in 56 studies of sexual risk behavior: review and recommendations, Archives of Sexual Behavior, 2006, 35(3):327-345.

16. Sutherland EG et al., Contraceptive needs of female sex workers in Kenya-a cross-sectional study, European Journal of Contraception $\mathcal{E}$ Reproductive Health Care, 2011, 16(3):173-182.

17. Reed JB et al., Estimating national HIV incidence from directly observed seroconversions in the Swaziland HIV Incidence Measurement Survey (SHIMS) longitudinal cohort, paper presented at the XIX International AIDS Conference, Washington, DC, USA, July 22-27, 2012.

18. Central Statistical Office (CSO) and Macro International, Swaziland Demographic and Health Survey, 2006-2007, Mbabane, Swaziland: CSO and Macro International, 2008.

19. Heckathorn DD, Respondent-driven sampling: a new approach to the study of hidden populations, Social Problems, 1997, 44(2):174-199.

20. Salganik MJ and Heckathorn DD, Sampling and estimation in hidden populations using respondent-driven sampling, Sociological Methodology, 2004, 34(1):193-240.

21. Schonlau M and Liebau E, Respondent driven sampling, Research Notes, Berlin, Germany: German Data Forum, 2010, No. 45.

22. Oanda Corporation, Currency converter: historical exchange rates, <http://www.oanda.com/currency/historical-rates>, accessed June 5, 2012

23. Diaz T, Schable B and Chu SY, Relationship between use of condoms and other forms of contraception among human immunodeficiency virus-infected women, Obstetrics \& Gynecology, 1995, 86(2):277-282.

24. Carrieri MP et al., Oral contraception and unprotected sex with occasional partners of women HIV-infected through injection drug use, AIDS Care, 2006, 18(7):795-800.

25. de Visser R and Smith A, Relationship between sexual partners influences rates and correlates of condom use, AIDS Education and Prevention, 2001, 13(5):413-427.

26. de Walque D and Kline R, Variations in condom use by type of partner in 13 Sub-Saharan African countries, Studies in Family Planning, 2011, 42(1):1-10.

27. Feldblum PJ et al., Pregnancy among sex workers participating in a condom intervention trial highlights the need for dual protection, Contraception, 2007, 76(2):105-110.

28. Salganik MJ, Commentary: respondent-driven sampling in the real world, Epidemiology, 2012, 23(1):148-150.
29. McCreesh $\mathrm{N}$ et al., Evaluation of respondent-driven sampling, Epidemiology, 2012, 23(1):138-147.

30. Spaulding $A B$ et al., Linking family planning with HIV/AIDS interventions: a systematic review of the evidence, AIDS, 2009, 23(Suppl. 1):S79-S88.

31. Reynolds HW, Steiner MJ and Cates W, Jr., Contraception's proved potential to fight HIV, Sexually Transmitted Infections, 2005 81(2):184-185.

32. Wilcher R et al., From effectiveness to impact: contraception as an HIV prevention intervention, Sexually Transmitted Infections, 2008, 84(Suppl. 2):ii54-ii60.

\section{RESUMEN}

Contexto: Las trabajadoras sexuales tienen un mayor riesgo de infección por VIH como de embarazo no deseado. Los métodos anticonceptivos modernos distintos a los de barrera son altamente efectivos en la prevención del embarazo, pero no ofrecen protección contra el VIH. Se necesita una mejor comprensión del uso que hacen las trabajadoras sexuales de los condones y de los métodos distintos a los de barrera para ayudarles a satisfacer sus necesidades anticonceptivas y de protección contra las ITS.

Métodos: Una encuesta realizada en 2011 basada en un muestreo y dirigida por la persona entrevistada, recolectó datos de salud reproductiva y de uso de anticonceptivos de 325 trabajadoras sexuales en Suazilandia. Se utilizó un análisis de regresión logística multinomial para identificar asociaciones entre características seleccionadas y cuatro resultados relativos al uso de anticonceptivos durante el mes anterior: uso consistente del condón solamente; uso de anticonceptivo moderno que no es de barrera (ya sea solo o con un uso inconsistente del condón); uso de dos métodos; y uso inconsistente del condón, uso de otro método o de ningún método. Las probabilidades predichas ajustadas también se calcularon para determinar patrones de asociación.

Resultados: Después de realizar ajustes por factores contextuales y conductuales, se encontró que el 16\% de las trabajadoras sexuales eran usuarias consistentes del condón solamente; $38 \%$ eran usuarias inconsistentes del condón o usaban otro método o ningún método; $39 \%$ usaba métodos modernos distintos a los de barrera (sin uso consistente del condón); y 8\% eran usuarias de dos métodos. Las mujeres que reportaron haber experimentado una falla reciente con el condón tuvieron menos probabilidades que otras de ser usuarias consistentes del condón (6\% vs. 22\%). El uso consistente solamente de condones fue más común en mujeres que no habian tenido parejas no comerciales en el pasado mes, que en aquellas que reportaron haber tenido dos o más de esas parejas (39\% vs. 3\%). Además, las personas entrevistadas que tenían hijos tuvieron más probabilidades que sus contrapartes nuliparas de reportar el uso de métodos distintos a los de barrera solamente (65\% vs. 14\%).

Conclusiones: El nivel considerable de uso inconsistente o de no uso del condón en usuarias de anticonceptivos distintos a los de barrera subraya la necesidad de incorporar la prevención del VIH en las intervenciones de planificación familiar, especialmente entre trabajadoras sexuales que tienen hijos $y$ parejas no comerciales. 


\section{RÉSUMÉ}

Contexte: Les travailleuses du sexe courent un risque accru de contraction du VIH comme de grossesse non désirée. La contraception moderne sans barrière atteint de hauts niveaux d'efficacité en termes de prévention de la grossesse, sans toutefois offrir de protection contre le VIH. Une meilleure compréhension de l'usage du préservatif et des méthodes sans barrière parmi les travailleuses du sexe est nécessaire si l'on veut les aider à satisfaire à leurs besoins de contraception et de protection contre les IST.

Méthodes: En 2011, une enquête basée sur unéchantillonnage en fonction des répondants a servi à la collecte de données de santé reproductive et de pratique contraceptive auprès de 325 travailleuses du sexe au Swaziland. L'analyse de régression logistique multinomiale a permis d'identifier les associations entre les caractéristiques sélectionnées et quatre résultats de pratique contraceptive durant le mois écoulé avant l'enquête: usage régulier du préservatif seul; pratique contraceptive moderne sans barrière (soit seule, soit avec usage irrégulier du préservatif); pratique de méthode double; et usage irrégulier du préservatif, pratique d'une autre méthode ou absence totale de méthode. Les probabilités prédites corrigées ont aussi été calculées pour déterminer les tendances d'association.

Résultats: Sous correction de facteurs socioculturels et comportementaux, 16\% des travailleuses se sont avérées utiliser régulièrement le préservatif seul; 38\% l'utilisaient de manière irrégulière, pratiquaient d'autres méthodes ou n'en pratiquaient aucune; 39\% pratiquaient une méthode moderne sans barrière (sans usage régulier du préservatif) et $8 \%$ pratiquaient une méthode double. Les femmes ayant déclaré un échec récent du préservatif se sont révélées moins susceptibles que les autres d'utiliser régulièrement la méthode (6\% par rapport à 22\%). L'usage régulier du préservatif seul paraît plus courant parmi les femmes qui n'avaient pas eu de partenaires non commerciaux durant le dernier mois écoulé, par rapport à celles ayant déclaré au moins deux partenaires non commerciaux (39\% par rapport à 3\%). De plus, les répondantes mères se sont révélées plus susceptibles que leurs homologues nullipares de déclarer la pratique de méthodes sans barrière seulement (65\% par rapport à $14 \%$ ).

Conclusions: Le niveau considérable d'usage irrégulier ou nul du préservatif parmi les utilisatrices de la contraception sans barrière souligne la nécessité d'incorporer la prévention $d u V I H$ dans les interventions de planification familiale, en particulier parmi les travailleuses du sexe qui ont des enfants et des partenaires non commerciaux.

\section{Acknowledgments}

This research was supported by Project SEARCH, which was funded by the U.S. Agency for International Development under contract GHH-I-00-07-00032-00, and by the President's Emergency Plan for AIDS Relief. The authors thank the community of female sex workers who embraced this research project and assisted in study planning and dissemination. We thank Rebecca Miller and Darrin Adams for their leadership in project implementation, and Virginia Tedrow and Mark Berry for supporting implementation. We acknowledge Babazile Dlamini, Edward Okoth and Jessica Greene for their leadership in conducting this study. We also thank the Swaziland Most-at-Risk Populations technical working group, the Swaziland Ministry of Health and other Swazi government agencies that provided valuable guidance and helped ensure the success of the study.

Author contact: eyam@popcouncil.org 